\title{
Time series analysis of death of residents with malignant granules in Shenyang, China
}

\author{
BINGYU LI ${ }^{1,2}$, SHUYIN LI $^{2}$, CHUNLING XIAO ${ }^{1,2}$, CHUNQING ZHANG $^{3}$, \\ JIANPING CHEN ${ }^{3}$, HONG LIN ${ }^{4}$, YIMING DU ${ }^{4}$ and MIN LIU ${ }^{4}$ \\ ${ }^{1}$ Department of Pathogenic Biology, Shenyang Medical College; ${ }^{2}$ Key Laboratory of Environmental Pollution \\ and Microecology of Liaoning Province, Shenyang Medical College, Shenyang, Liaoning 110034; \\ ${ }^{3}$ Shenyang Center for Disease Control and Prevention, Shenyang, Liaoning 110031; ${ }^{4}$ Shenyang \\ Environmental Monitoring Center Station, Shenyang, Liaoning 110016, P.R. China
}

Received April 11, 2018; Accepted July 5, 2018

DOI: $10.3892 / \mathrm{ol} .2018 .9186$

\begin{abstract}
The aim of the study was to find out the association between air pollution and meteorological conditions with the death of residents living in Shenyang due to malignant tumors. Tumor related death data of residents of five urban districts in Shenyang were obtained from Shenyang Center for Disease Control and Prevention. Daily temperature, pressure, wind speed and humidity data of Shenyang from 2010 to 2015 were obtained from Shenyang Meteorological Bureau. Urban air pollution data were obtained from the Shenyang Environmental Monitoring Center Station, Shenyang Environmental Protection Bureau of China. All data were analyzed by the Poisson regression model. During the period from 2010 to 2015, the number of deaths among malignancies in Shenyang was $215,141,000$, and the death rate of malignancies in Shenyang was increasing year by year from 2010 to 2015. Mortality rate is higher in men than in women, and mortality rate increased with aging and the highest mortality rate was observed in the 75-80 years age group. Average concentration of aerodynamic diameter of $<10 \mu \mathrm{m}$ particles, the aerodynamic diameter of $<2.5 \mu \mathrm{m}$ particles, sulfur dioxide $\left(\mathrm{SO}_{2}\right)$ and nitrogen dioxide $\left(\mathrm{NO}_{2}\right)$ was $122.37,74.75,79.36$, and $47.65 \mu \mathrm{g} / \mathrm{m}^{3}$, respectively. After control of confounding factors, it was observed that every $10 \mu \mathrm{g} / \mathrm{m}^{3}$ increase of PM2.5 is followed by the $0.024 \%$ (95\% confidence interval: $0.005 \%$ and $0.043 \%$ ) increase of malignant tumor mortality rate. The results show that the increase of air pollution is related to the number of malignant tumors-related deaths in Shenyang, China, and season, sex and age are also influencing factors.
\end{abstract}

Correspondence to: Dr Chunling Xiao, Department of Pathogenic Biology, Shenyang Medical College, 146 Huang Hebei Street, Shenyang, Liaoning 110034, P.R. China

E-mail: xiaochunling2000@163.com; xiaochunling@symc.edu.cn

Key words: fine particulate matter, malignant neoplasms, mortality rate

\section{Introduction}

The industrialization process in China aggregated environmental pollution (1). Signs of extreme pollution, such as extremely high PM2.5 levels, are frequently observed in major cities of China, such as Beijing (2). Air pollution caused by a series of environmental health issues has attracted more and more attentions. Airborne particulate matter (PM) is a mixture of gaseous or liquid particulate matter that floats in the air (3). Inhalable particles are classified into three categories: coarse particles $(\mathrm{d}=2.5-10 \mu \mathrm{m})$, fine particles $(\mathrm{d}=0.1-2.5 \mu \mathrm{m})$, and very fine particles $(\mathrm{d}<0.1 \mu \mathrm{m})(4)$. Studies have shown that the main chemical constituents of respirable particulate matter can be divided into four major categories: soluble components (mostly inorganic ions), organic components, trace elements and carbon elements. In 1994, the American Cancer Institute (ICR) reported that particles $>10 \mu \mathrm{m}$ cannot enter the respiratory tract, particles between 5-10 $\mu \mathrm{m}$ are basically blocked in the upper respiratory tract, particles $<5 \mu \mathrm{m}$ can enter the alveoli and bronchi, and fine particles $<2.5 \mu \mathrm{m}$ can easily enter the alveoli (5). PM2.5 can be suspended in the atmosphere for a long time, and can even stay up to 30 days. During this period, due to the small gravitational effect of PM2.5 and large specific surface area, it can adsorb a variety of complex components, such as a variety of toxic substances, heavy metal compounds, pathogens, bacteria and other microorganisms (6). PM2.5 induces genotoxicity (DNA damage), oxidative stress and inflammation (7-10). Epidemiological studies have confirmed the significant correlations between particulate air pollution and various adverse health effects (11). Several landmark review studies have shown that exposure to PM2.5 is associated with premature death and increased incidence of respiratory and cardiovascular disease $(12,13)$. Accurate environment PM2.5 concentration measurements are critical to epidemiological studies of chronic human exposure, but also are big challenges (14).

At present, most studies have linked air pollution to cardiovascular and respiratory disease, but studies on the association between air pollutants and malignancies are rare. Therefore, this study analyzed the association between air pollutants and 
the death resulting from malignant tumors from 2010 to 2015 in Shenyang, China.

\section{Patients and methods}

Health data. We analyzed data of malignant tumor-related deaths in five urban areas in Shenyang, China from 2010 to 2015. The data were obtained from the Shenyang Center for Disease Control and Prevention statistics. Between 2010-2015, 48,084 people (27,987 men, 20,097 women) people died of malignant tumors. Mortality data are recorded according to the 10th edition of the International Classification of Diseases and Related Health Statistics. The protocol of this study has been approved by the Ethics Committee of Shenyang Medical College (Shenyang, China). All patients signed informed consent.

Exposure data. According to the Environmental Air Quality Standard' established in China in 2013, the average concentration of air fine particles (PM2.5) and ozone $\left(\mathrm{O}_{3}\right)$ was added to the original sulfur dioxide $\left(\mathrm{SO}_{2}\right)$, nitrogen dioxide $\left(\mathrm{NO}_{2}\right)$ carbon monoxide (CO), respirable particulate matter (PM10) monitoring indicators. The daily air pollution data used in this study include continuous monitoring of PM2.5, PM10, $\mathrm{SO}_{2}, \mathrm{NO}_{2}$ concentrations in five urban districts in Shenyang. PM2.5 data are only available between 2013-2015, and other pollutant data covered 2013-2015. Those data were obtained from Shenyang Environmental Monitoring Center Station and Shenyang Environmental Protection Bureau of China. Daily average temperature, wind speed, pressure and relative humidity and other weather data from 2010 to 2015 were provided by Shenyang Meteorological Bureau.

Data analysis. The health and exposure data of this study were used to predict the association between atmospheric particulate exposure and malignancy mortality using a generalized linear model (GAM) based on the Poisson distribution combined with time sequence analysis using the time sequence analysis, The function of estimating the possible hysteresis effect of air pollution. Based on the generalized cross-validation (GCV) selection of the degree of freedom (df) of the lag results, the most suitable model with $7 \mathrm{df}$ is found (lag 0-6). Data are stratified according to different seasons (warm season, May-October; winter, November-April). The number of deaths from malignant tumors varies with the concentration of PM in the environment as follows: $\operatorname{LogE}(\mathrm{Yt})=\operatorname{para}\left(\mathrm{SO}_{2}\right.$, $\mathrm{NO}_{2}$, PM10, PM2.5) + spline(year, df) + spline(mouth, df) + spline(temperature, df) + spline(hunidity, df) + dow + holiday $+\alpha \mathrm{PM}_{\mathrm{t}-1, \mathrm{t}}$.

Where $\mathrm{E}(\mathrm{Yt})$ represents the number of expected malignancies on day $t$, the spline is a natural cubic spline, and $\mathrm{PM}_{\mathrm{t}-1}$ represents the mean 2-day concentration at days $t$ and 1 . First, the hysteresis effect of air pollution was tested by single-day lag. The most likely lag time was then determined after the establishment of a single contaminant model. The effect of each pollutant additional $10 \mu \mathrm{g} / \mathrm{m}^{3}$ on the death of malignant tumors at different times was analysed. Since PM2.5 data are provided only between 2013-2015, all analyses in this study for PM2.5 are only valid for those 3 years. Statistical analysis of this study was performed using VR3-2.5 (R Project
Table I. Daily air pollutants, meteorological conditions, and number of malignant tumor deaths in Shenyang, China between 2010-2015, are shown throughout the year and in the cold and warm season ${ }^{\mathrm{a}}$.

\begin{tabular}{lccc}
\hline Variables & All & Cold & Warm \\
\hline $\begin{array}{l}\text { No. of cancer } \\
\text { deaths }\end{array}$ & $22.27 \pm 4.98$ & $21.93 \pm 4.98$ & $22.6 \pm 4.96$ \\
$\mathrm{SO}_{2}$ & $79.36 \pm 81.05$ & $132.83 \pm 85.3$ & $26.76 \pm 17.26$ \\
$\mathrm{PM}_{0}$ & $122.37 \pm 81.33$ & $149.92 \pm 93.3$ & $95.26 \pm 55.56$ \\
$\mathrm{NO}_{2}$ & $47.65 \pm 18.2$ & $52.53 \pm 20.56$ & $42.85 \pm 13.98$ \\
$\mathrm{PM}_{2.5}$ & $74.75 \pm 61.8$ & $96.53 \pm 71.09$ & $53.32 \pm 41.05$ \\
Relative humidity & $62.81 \pm 15.56$ & $58.6 \pm 15.67$ & $66.94 \pm 14.31$ \\
Temperature & $8.78 \pm 13.19$ & $-2.07 \pm 8.94$ & $19.45 \pm 6.07$ \\
\hline
\end{tabular}

${ }^{\text {aPM}}$ 2.5 data are only collected between 2013-2015. $\mathrm{SO}_{2}$, sulfur dioxide; $\mathrm{NO}_{2}$, nitrogen dioxide.

for Statistical Computing), GraphPad Prism 7 (GraphPad Software, NY, USA) and SPSS 22.0 (IBM Corp., Armonk, NY, USA).

\section{Results}

In $<$ this study, to the best of our knowledge, we first summarized the meteorological, environmental and death statistical data collected during the 2010-2015 period. Table I summarizes the number of malignant tumor deaths, concentrations of $\mathrm{SO}_{2}$, $\mathrm{PM} 10, \mathrm{NO}_{2}$ and PM2.5, relative humidity, and temperature during the period of 2010-2015 in Shenyang. Results showed that the average $\mathrm{SO}_{2}, \mathrm{PM} 10, \mathrm{NO}_{2}$ and $\mathrm{PM} 2.5$ concentrations were $122.37 \mu \mathrm{g} / \mathrm{m}^{3}, 74.75 \mu \mathrm{g} / \mathrm{m}^{3}, 79.36 \mu \mathrm{g} / \mathrm{m}^{3}$, and $47.65 \mu \mathrm{g} / \mathrm{m}^{3}$, respectively. In the warm season, the number of deaths caused by malignant tumors is greater than that in the cold season. PM2.5 and PM10 in the cold season (96.53 and $149.92 \mu \mathrm{g} / \mathrm{m}^{3}$ ) are higher than those in the warm season. In Shenyang, China, the average temperature is $-2.07^{\circ} \mathrm{C}$ during cold season and is $19.45^{\circ} \mathrm{C}$ during the warm season. Fig. 1 shows the concentrations of PM2.5, PM10, $\mathrm{SO}_{2}$ and $\mathrm{NO}_{2}$, relative humidity and temperature in Shenyang, China, and higher values of those factors were found in the cold season than in the warm season. In the analysis of the interrelationships between different air pollutants and meteorological factors, it was found that there were significant correlations between the four major air pollutants, such as the correlation between PM2.5 and PM10 and the correlation between temperature and relative humidity (Table II).

Analysis of different age groups showed no significant differences in the number of deaths among groups younger than 40 years. Mortality rate increased with aging after 40 years and two peaks were observed in the 55-60 and 75-80 age groups (Fig. 2). Mortality rate reached 19.51/100,000 in the 75-80 age group. No significant effects of PM10 and PM2.5 on malignant tumor mortality rate were observed (Fig. 3).

Table III shows the impact of several pollutants on the mortality of malignant tumors in different seasons. We found that the impact of increased PM exposure on mortality was more significant in the warm season. After controlling the 

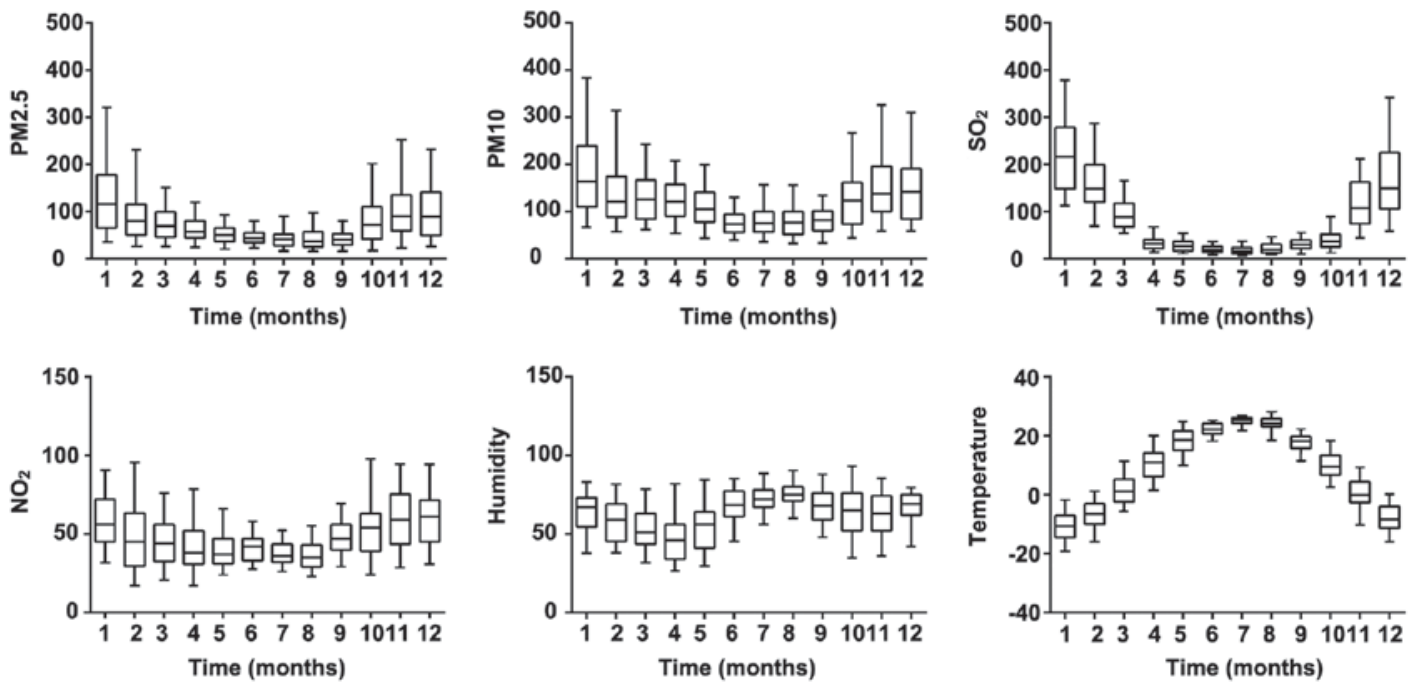

Figure 1. China Shenyang PM2.5, $\mathrm{PM} 10, \mathrm{SO}_{2}, \mathrm{NO}_{2}$, relative humidity, temperature, box diagram. Data only 2013-2015. $\mathrm{SO}_{2}$, sulfur dioxide; $\mathrm{NO}_{2}$, nitrogen dioxide.

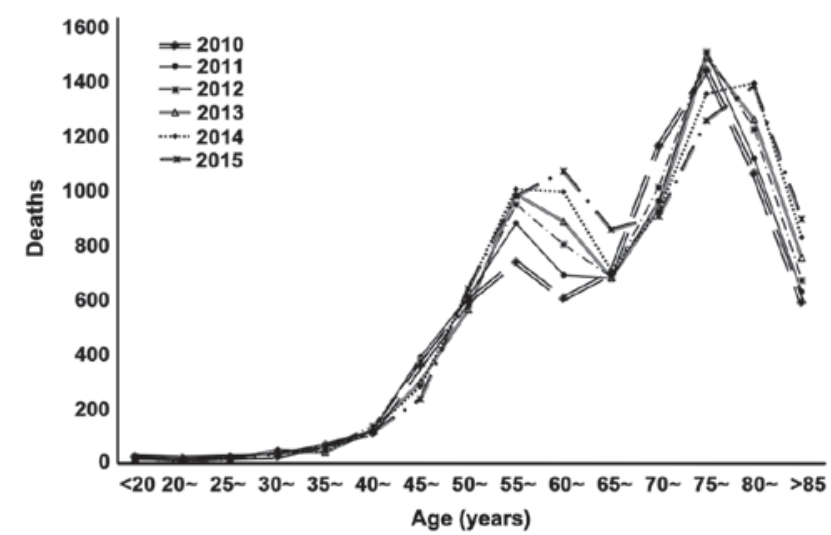

Figure 2. Trends in the number of deaths from malignant tumors from 2010 to 2015.

confounding factors, PM2.5 increased mortality by $0.024 \%$ for each $10 \mu \mathrm{g} / \mathrm{m}^{3}$ increase of PM2.5 in the warm season $(95 \% \mathrm{CI}$ : $0.005 \%, 0.043 \%$ ). The impact of pollutants on patients with malignant tumors is consistent with the data shown in Table I. These data show that PM2.5 has a greater impact on the death from malignant tumors during the warm season. Fig. 4 shows the effects of PM10 and PM2.5 on the mortality of patients with malignant tumors at different lag times. In addition, the impact of air pollutants on the death from malignant tumors is not significant; PM10 had a relatively great impact on the mortality from malignant tumors after lagging for 2 days, but it showed a decreasing trend after a lag of 3 days followed by another increasing trend. The lag effect of PM2.5 was weak, but there was a relatively great impact after lagging for 3 days.

\section{Discussion}

The 2013 China Cancer Registration Center survey results show that malignant tumors affect $\sim 3$ million cases in China every year (15). Many factors can stimulate the proliferation and differentiation of cancer cells (16), such as inhalation of air pollutants, long-term consumption of carcinogens contained in
Table II. Correlation analysis of air pollutants and meteorological conditions in Shenyang, China from 2010 to $2015^{\mathrm{a}}$.

\begin{tabular}{lcccccc}
\hline Variables & $\mathrm{SO}_{2}$ & $\mathrm{PM} 10$ & $\mathrm{NO}_{2}$ & $\mathrm{PM} 2.5$ & \multicolumn{2}{r}{ Temperature Humidity } \\
\hline $\mathrm{SO}_{2}$ & 1 & 0.65061 & 0.55956 & 0.67784 & -0.11304 & -0.79723 \\
$\mathrm{PM}_{10}$ & - & 1 & 0.60821 & 0.91044 & -0.04067 & -0.35945 \\
$\mathrm{NO}_{2}$ & - & - & 1 & 0.66465 & 0.06812 & -0.32731 \\
$\mathrm{PM} 2.5$ & - & - & - & 1 & 0.12740 & -0.40456 \\
Temperature & - & - & - & - & 1 & 018388 \\
Humidity & - & - & - & - & - & 1 \\
\hline
\end{tabular}

${ }^{\text {aPM}} 2.5$ data are only collected between 2013-2015. $\mathrm{SO}_{2}$, sulfur dioxide; $\mathrm{NO}_{2}$, nitrogen dioxide.

food as well as a long time exposure to high radiation areas. In recent years, due to the intensification of global air pollution, association between air pollution as well as the morbidity and mortality of various diseases has attracted more and more attention, and many studies have confirmed that air pollutants, especially air particulate matter, have a negative impact on human health (17-20).

In this study, we analyzed environmental, meteorological and death data in Shenyang from 2010 to 2015. The results show that the average daily death rate of malignant tumor patients in Shenyang (May-October) is relatively high. This conclusion is similar to the mortality rate from malignant tumors in Ningbo, China (3). Studies have shown that the warm season and air pollutants have a great impact on the death of malignant tumors $(21,22)$. Cold weather in winter inhibits patients' activity, and activities during the warm season may increase exposure to toxic substances; yet, the specific mechanism still remains unclear. However, some studies have shown that the impact of toxic substances on death from malignant tumors is strengthened by cold weather $(23,24)$, which may be explained by the different climate conditions, levels of pollutants and living environment. The average concentration of air pollutants between November and April (cold season) 
Table III. The effect of a single contaminated model on the mortality of malignant tumors ${ }^{\mathrm{a}}$.

\begin{tabular}{lrrr}
\hline Variables & \multicolumn{1}{c}{ All } & Cold & Warm \\
\hline $\mathrm{SO}_{2}$ & $0.00220(-0.00158,0.00600)$ & $0.00104(-0.00472,0.00683)$ & $0.01582(-0.00409,0.03613)$ \\
$\mathrm{PM}_{10}$ & $-0.00069(-0.00512,0.00377)$ & $0.00046(-0.00437,0.00532)$ & $-0.01700(-0.03116,-0.00255)$ \\
$\mathrm{NO}_{2}$ & $0.005622548(-0.00662,0.01801)$ & $0.008854975(-0.01170,0.02983)$ & $0.007209(-0.01331,0.02815)$ \\
$\mathrm{PM}_{2.5}$ & $-0.00106703(-0.00722,0.00512)$ & $-0.004620493(-0.01147,0.00228)$ & $0.023881(0.00502,0.04310)^{\mathrm{b}}$ \\
\hline
\end{tabular}

${ }^{\mathrm{a}}$ This was indicated by an increase of $10 \mu \mathrm{g} / \mathrm{m}^{3}$ of air pollutant concentration in cold and warm seasons; ${ }^{\mathrm{b}} \mathrm{SO}_{2}$, sulfur dioxide; $\mathrm{NO}_{2}$, nitrogen dioxide.
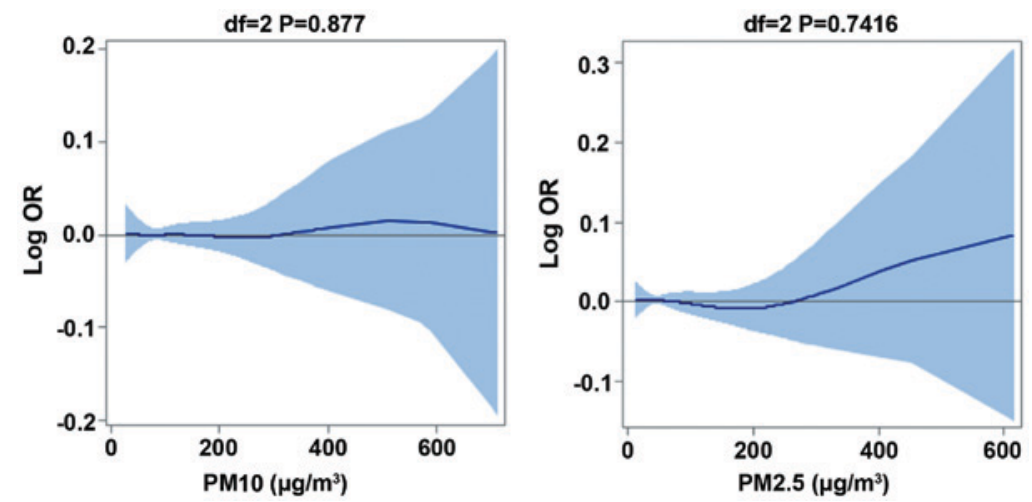

Figure 3. Effects of PM10 and PM2.5 on the death from malignancies in Shenyang residents. PM10 and PM2.5 use 2013-2015 data.

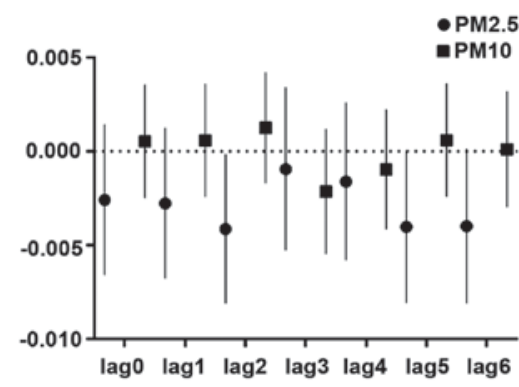

Figure 4. Effects of PM2.5 and PM10 on the mortality from malignant tumors.

is high, which may be caused by the consumption of coal in Shenyang, China. Studies have found that those pollutants can cause an increase in the incidence of respiratory and cardiovascular disease (25-28). Xu et al (29) proved that PM2.5 and respiratory diseases are closely associated in Bejing, China. Haley et al (30) found that PM2.5 has a great impact on heart failure in New York, United States, and the effect is more significant on elderly than on young individuals. The effects of air pollutant exposure on the cardiovascular and respiratory system have been extensively investigated, while the effects of cancer still remain unclear, possibly due to the complex pathogenesis.

The analysis of different age groups showed no significant differences in the number of deaths among groups younger than 40 years. On the contrary, the mortality rate increased with aging after 40 years and two peaks were observed in the 55-60 and 75-80 age groups. In fact, the mortality rate reached $19.51 / 100,000$ in the 75-80 age group. The high mortality rate of tumors in Shengyang is related to the severe air pollution conditions due to the development of heavy industry in the past decades. With the growth of the aging population in China, the mortality rate due to tumors is predicted to be further increased.

After controlling the confounding factors, it was observed that every $10 \mu \mathrm{g} / \mathrm{m}^{3}$ increase of PM2.5 in the warm season is followed by a $0.024 \%$ (95\% confidence interval: $0.005 \%$ and $0.043 \%$ ) increase in the malignant tumor mortality rate. However, the lagging effect of pollutants is not obvious. The obvious impact was observed only after lagging for 2 days. However, there are still some limitations in this study. There are too many uncontrollable factors in the course of malignant tumors, such as smoking and alcohol stimulation which can also increase the risk of death from malignant tumors.

In summary, the levels of PM10 and PM2.5-based air particulate matter are related to the death from malignant tumors from 2010 to 2015 in Shenyang, China. The improvement of environmental conditions is urgently needed to reduce the mortality rate due to malignant tumors.

\section{Acknowledgements}

Not applicable.

\section{Funding}

No funding was received.

\section{Availability of data and materials}

The datasets used and/or analyzed during the present study are available from the corresponding author on reasonable request. 


\section{Authors' contributions}

BL drafted this manuscript. BL, SL and CX were mainly devoted to collecting and interpreting health data. BL, CZ and JC analyzed and interpreted exposure data. HL, YD and ML were responsible for statistical analysis. All authors have read and approved the final manuscript.

\section{Ethics approval and consent to participate}

This study has been approved by the Ethics Committee of Shenyang Medical College (Shenyang, China). All patients signed informed consent.

\section{Patient consent for publication}

Not applicable.

\section{Competing interests}

The authors declare that they have no competing interests.

\section{References}

1. Chan CK and Yao X: Air pollution in mega cities in China. Atmos Environ 42: 1-42, 2008.

2. Becker S and Soukup J: Coarse(PM 2.5-10), fine(PM 2.5), and ultrafine air pollution particles induce/increase immune costimulatory receptors on human blood-derived monocytes but not on alveolar macrophages. J Toxicol Environ Health (Part A) 66 : 847-859, 2003.

3. He T, Yang Z, Liu T, Shen Y, Fu X, Qian X, Zhang Y, Wang Y, $\mathrm{Xu} \mathrm{Z}$, Zhu S, et al: Ambient air pollution and years of life lost in Ningbo, China. Sci Rep 6: 22485, 2016.

4. Sun Q, Hong X and Wold LE: Cardiovascular effects of ambient particulate air pollution exposure. Circulation 121: 2755-2765, 2010.

5. Weichenthal SA, Godri-Pollitt K and Villeneuve PJ: PM2.5, oxidant defence and cardiorespiratory health: A review. Environ Health 12: 40, 2013.

6. Seaton A, MacNee W, Donaldson K and Godden D: Particulate air pollution and acute health effects. Lancet 345: 176-178, 1995.

7. Zhao H, Yang B, Xu J, Chen DM and Xiao CL: PM2.5-induced alterations of cell cycle associated gene expression in lung cancer cells and rat lung tissues. Environ Toxicol Pharmacol 52: 77-82, 2017.

8. Líbalová H, Krčková S, Uhlírová K, Kléma J, Ciganek M, Rössner P Jr, Šrám RJ, Vondráček J, Machala M and Topinka J: Analysis of gene expression changes in A549 cells induced by organic compounds from respirable air particles. Mutat Res 770: 94-105, 2014

9. Wang G, Zhao J, Jiang R and Song W: Rat lung response to ozone and fine particulate matter (PM2.5) exposures. Environ Toxicol 30: 343-356, 2015.

10. Vattanasit U, Navasumrit P, Khadka MB, Kanitwithayanun J, Promvijit J, Autrup H and Ruchirawat M: Oxidative DNA damage and inflammatory responses in cultured human cells and in humans exposed to traffic-related particles. Int J Hyg Environ Health 217: 23-33, 2014.

11. Ye X, Peng L, Kan H, Wang W, Geng F, Mu Z, Zhou J and Yang D: Acute effects of particulate air pollution on the incidence of coronary heart disease in Shanghai, China. PLoS One 11: e0151119, 2016.

12. Schwartz J: Harvesting and long term exposure effects in the relation between air pollution and mortality. Am J Epidemiol 151: $440-448,2000$.
13. Katanoda K, Sobue T, Satoh H, Tajima K, Suzuki T, Nakatsuka H, Takezaki T, Nakayama T, Nitta H, Tanabe K, et al: An association between long-term exposure to ambient air pollution and mortality from lung cancer and respiratory diseases in Japan. J Epidemiol 21: 132-143, 2011.

14. Fu J, Jiang D, Lin G, Liu K and Wang Q: An ecological analysis of PM2.5 concentrations and lung cancer mortality rates in China. BMJ Open 5: e009452, 2015.

15. Zheng $\mathrm{Y}$ and $\mathrm{Wu} \mathrm{C}$ : Prevalence and trend of gastrointestinal malignant tumors in the elderly over 75 years old in China. Zhonghua Wei Chang Wai Ke Za Zhi 19: 481-485, 2016 (In Chinese).

16. Demetriou CA, Raaschou-Nielsen O, Loft S, Møller P, Vermeulen R, Palli D, Chadeau-Hyam M, Xun WW and Vineis P: Biomarkers of ambient air pollution and lung cancer: A systematic review. Occup Environ Med 69: 619-627, 2012.

17. Hoek G, Krishnan RM, Beelen R, Peters A, Ostro B, Brunekreef B and Kaufman JD: Long-term air pollution exposure and cardio-respiratory mortality: A review. Environ Health 12: 43, 2013.

18. Viera L, Chen K, Nel A and Lloret MG: The impact of air pollutants as an adjuvant for allergic sensitization and asthma. Curr Allergy Asthma Rep 9: 327-333, 2009.

19. Zhang JJ,McCreanor JE, Cullinan P, Chung KF, Ohman-Strickland P, Han IK, Järup L and Nieuwenhuijsen MJ: Health effects of real-world exposure to diesel exhaust in persons with asthma. Res Rep Health Eff Inst 138: 5-123, 2009.

20. Lindgren A, Stroh E, Nihlén U, Montnémery P, Axmon A and Jakobsson K: Traffic exposure associated with allergic asthma and allergic rhinitis in adults. A cross-sectional study in southern Sweden. Int J Health Geogr 8: 25, 2009.

21. Peng RD, Dominici F, Pastor-Barriuso R, Zeger SL and Samet JM: Seasonal analyses of air pollution and mortality in 100 US cities. Am J Epidemiol 161: 585-594, 2005.

22. Ren $\mathrm{C}$ and Tong $\mathrm{S}$ : Temperature modifies the health effects of particulate matter in Brisbane, Australia. Int J Biometeorol 51: 87-96, 2006.

23. Li P, Xin J, Wang Y, Wang S, Shang K, Liu Z, Li G, Pan X, Wei L and Wang M: Time-series analysis of mortality effects from airborne particulate matter size fractions in Beijing. Atmos Environ 81: 253-262, 2013.

24. Cheng Y and Kan H: Effect of the interaction between outdoor air pollution and extreme temperature on daily mortality in Shanghai, China. J Epidemiol 22: 28-36, 2012.

25. Zhang LW, Chen X, Xue XD, Sun M, Han B, Li CP, Ma J, Yu H, Sun ZR, Zhao LJ, et al: Long-term exposure to high particulate matter pollution and cardiovascular mortality: A 12-year cohort study in four cities in northern China. Environ Int 62: 41-47, 2014

26. Chang X, Zhou L, Tang M and Wang B: Association of fine particles with respiratory disease mortality: A meta-analysis. Arch Environ Occup Health 70: 98-101, 2015.

27. Beelen R, Hoek G, van den Brandt PA, Goldbohm RA, Fischer P, Schouten LJ, Armstrong B and Brunekreef B: Long-term exposure to traffic-related air pollution and lung cancer risk. Epidemiology 19: 702-710, 2008.

28. Mills NL, Donaldson K, Hadoke PW, Boon NA, MacNee W, Cassee FR, Sandström T, Blomberg A and Newby DE: Adverse cardiovascular effects of air pollution. Nat Clin Pract Cardiovase Med 6: 36-44, 2009

29. Xu Q, Li X, Wang S, Wang C, Huang F, Gao Q, Wu L, Tao L, Guo J, Wang W, et al: Fine particulate air pollution and Hospital Emergency Room visits for respiratory disease in urban areas in Beijing, China, in 2013. PLoS One 11: e0153099, 2016.

30. Haley VB, Talbot TO and Felton HD: Surveillance of the short-term impact of fine particle air pollution on cardiovascular disease hospitalizations in New York State. Environ Health 8: 42, 2009.

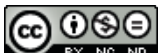

This work is licensed under a Creative Commons Attribution-NonCommercial-NoDerivatives 4.0 International (CC BY-NC-ND 4.0) License. 